This is the final peer-reviewed accepted manuscript of

FABBRI, ELENA: Pharmaceuticals in the environment: expected and unexpected effects on aquatic fauna.

ANNALS OF THE NEW YORK ACADEMY OF SCIENCES, 1340. ISSN 0077-8923.

DOI: $10.1111 /$ nyas.12605

The final published version is available online at: $\mathrm{http}: / / \mathrm{dx}$. doi.org/10.1111/nyas.12605

Rights / License:

The terms and conditions for the reuse of this version of the manuscript are specified in the publishing policy. For all terms of use and more information see the publisher's website.

This item was downloaded from IRIS Università di Bologna (https://cris.unibo.it/)

When citing, please refer to the published version. 


\title{
Pharmaceuticals in the environment: expected and unexpected effects on aquatic fauna
}

\author{
Elena Fabbri \\ Department of Biological, Geological and Environmental Sciences, University of Bologna, Campus of Ravenna, Ravenna, Italy \\ Address for correspondence: Elena Fabbri, Department of Biological, Geological and Environmental Sciences, University of \\ Bologna, Campus of Ravenna, via S. Alberto 163, 48123 Ravenna, Italy. elena.fabbri@unibo.it
}

\begin{abstract}
A growing database reports that human and veterinary pharmaceutical residues are present in aquatic and terrestrial environments worldwide. Evidence indicates that nontarget organisms may be chronically exposed to low (ng/L to

$\mu \mathrm{g} / \mathrm{L}$ range) concentrations of a variety of pharmaceuticals, but that even these concentrations may result in significant biological effects. Here are briefly summarized well-documented examples demonstrating how pharmaceuticals behave differently from conventional pollutants, which suggests that they must be considered when risk to ecosystems and human health is assessed. In particular, examples are presented of expected effects related to the therapeutic mode of action, unwanted/side effects mainly related to oxidative stress, and unexpected effects induced by environmental concentrations of pharmaceuticals in aquatic animals. A list of the most relevant reviews on the subject is also provided to provide a more complete perspective on the effects of environmental pharmaceuticals in nontarget species.
\end{abstract}

Keywords: environmental pharmaceuticals; mode of action; oxidative stress; fish; invertebrates

\section{Background}

The issue of pharmaceutical residues in the environment was highlighted in the United States in the 1970 s, and in Europe (the UK) almost 10 years later. ${ }^{1}$ However, it has only been in the last decade that sophisticated analytical techniques have enabled detection at limits within the $\mathrm{ng} / \mathrm{L}$ range, and allowed researchers to quantify the number of pharmaceuticals in various water bodies, thus compelling the scientific community to consider such contamination as deserving attention. ${ }^{2}$

A growing database shows that pharmaceuticals are found in influents and effluents of sewage treatment plants (STPs) and in lakes and rivers, groundwater, and drinking water. ${ }^{3}$ Data are increasing for coastal waters, ${ }^{4}$ which have been generally neglected despite being a major receptor for wastewater owing to increasing human habitation of coastal areas and more intensive use of pharmaceuticals in aquaculture. Representatives of different pharmaceutical classes found in aquatic environments worldwide are reported in Figure 1. Monitoring concentrations and exposures to pharmaceuticals in terrestrial ecosystems are less well developed than in aquatic systems, but prescription drugsmainly antibiotics-are generally reported here as well. ${ }^{5}$

Large quantities of pharmaceuticals are produced and sold annually to be consumed by humans and animals worldwide. ${ }^{6}$ Subsequently, they are partially excreted as parental compounds or metabolites in an active form, ${ }^{3}$ which are spread into the environment in different ways, namely through STP effluents, water run-off from agricultural lands, and other means. STPs, even the most advanced, are not equipped to completely depurate sewage from pharmaceuticals, which remain in effluents at different concentrations. Routes followed by pharmaceuticals, from production to elimination, are illustrated in Figure 2.

Overall, the increased prescription rate and variety of pharmaceuticals prescribed and their incomplete depuration and limited biodegradability have raised concerns within the scientific community and the general public. ${ }^{7}$ Indeed, these substances, 


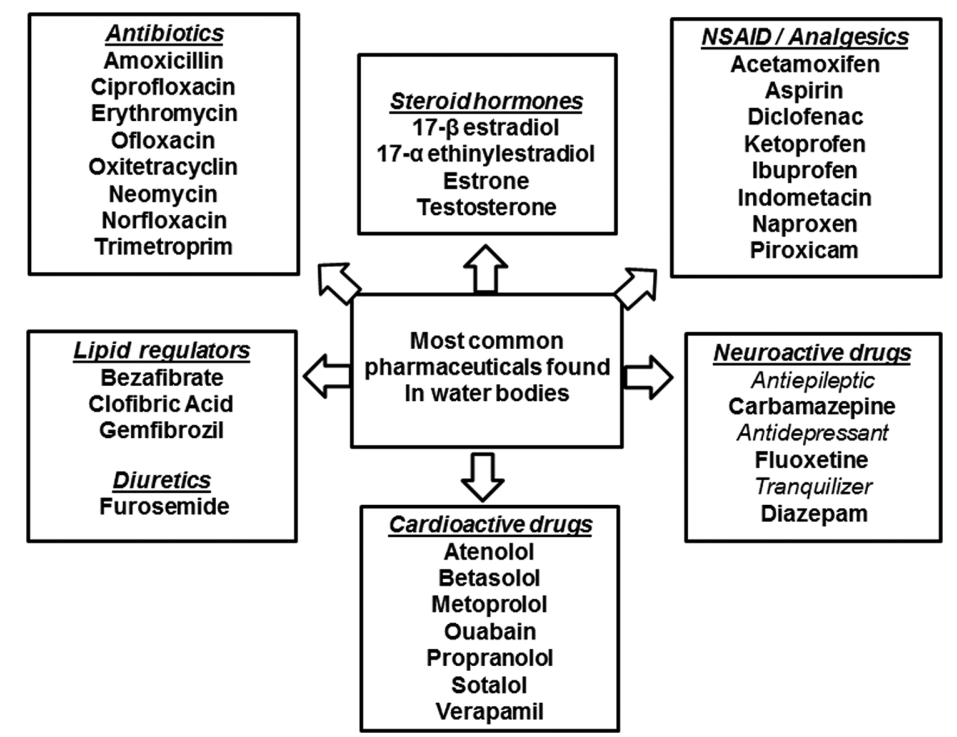

Figure 1. Examples of pharmaceuticals detected in aquatic bodies worldwide, at concentrations ranging from the low ng/L (potable waters) to $\mathrm{mg} / \mathrm{L}$ (STP effluents) ranges.

which are intended to improve the quality of human health, may cause unpredictable risks to the ecosystem and produce boomerang effects on public health through the diet or ingested water. ${ }^{7}$ The increasing phenomenon of antibiotic resistance has been related to the presence of low but consistent levels of these compounds in the environment. ${ }^{8}$

Evaluations of the potential effects of environmental pharmaceuticals on wildlife were initially based on chemical evidence, ${ }^{9}$ and for many years ecotoxicological standard tests led researchers to conclude that no harmful effects were expected at the concentrations routinely found in waters or soils. ${ }^{6}$ Such opinion has recently changed; and although acute toxicity remains uncommon at environmentally relevant concentrations, chronic effects are widely observed. ${ }^{3,6}$

Pharmaceuticals are known to significantly differ from conventional pollutants: for the most part they are conceived primarily to have biological effects at low doses and are resistant to inactivation before exerting their intended therapeutic effects. These same properties are paradoxically responsible for their bioaccumulation and toxic effects in aquatic and terrestrial ecosystems. ${ }^{6}$ Since pharmaceuticals are continuously discharged and not effectively depurated, ${ }^{10}$ exposure durations of aquatic organisms are persistent and increase with a decreased in-stream dilution. This scenario is locally exacerbated by the absence or inadequate functioning of depuration systems and by improper disposal.

The most significant examples of subtle effects of environmental pharmaceuticals are observed in fish, frogs, and crocodiles as a consequence of chronic exposure to $17 \beta$-estradiol and $17 \alpha$-ethynilestradiol, the active components of contraceptive pills. These medicines are among the most depurated by STPs, and only traces in the low $\mathrm{ng} / \mathrm{L}$ range are found in surface waters. Nevertheless, feminization effects on male vertebrates are well documented. ${ }^{3,6}$

Obviously, the reduction of pharmaceutical use by patients is unlikely and is not an option to ensure ecosystem quality. Therefore, the improvement of depuration systems is a major need, together with the increase of green pharmacy practices, application of targeted therapies aimed at reducing the consumption of drugs, substitution with more ecocompatible compounds, and appropriate disposal of unwanted drugs. In this regard, scientific research has recently focused on the identification of pharmaceuticals of greater concern and a search for conserved pathways in wildlife related to therapeutic mode of action (MoA). Investigations are also increasingly addressed to evaluate the display in nontarget aquatic fauna of those effects that are considered unwanted or side effects in patients. However, further alterations of physiological functions 


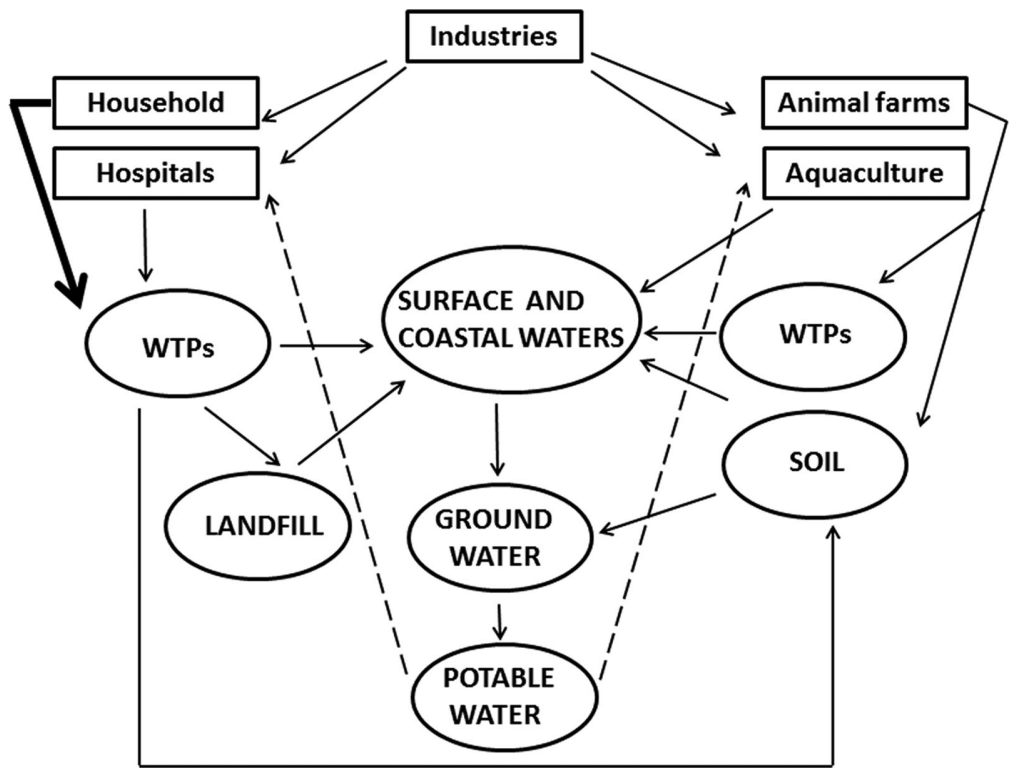

Figure 2. Scheme illustrating the fate of pharmaceuticals excreted by human and veterinary patients. The bold line underlines that household discharges represent by far the greatest contribution to the environment. Dashed lines highlight the possibility that drugs or their metabolites reaching potable waters might be recycled. WTPs, water treatment plants.

have been discovered in wildlife that were not anticipated from those known in human and veterinary medicine.

This paper presents a brief overview of MoArelated effects, unwanted/side effects, and some unexpected effects detected in aquatic animals after exposure to pharmaceutical residues, with the main goal to demonstrate how pharmaceuticals behave differently from conventional pollutants, and how, as such, they must be specifically considered when risk for ecosystem and human health is assessed.

\section{MoA-related effects of pharmaceuticals in aquatic animals}

An increasing body of evidence indicates that the capacity of a human pharmaceutical to cause an effect on nontarget vertebrates and invertebrates depends on the presence of drug-target orthologs in the animals. Among other examples, miconazole and promethazine, known to be calmodulin antagonists, induced correlated effects in Daphnia, where an ortholog of the human target calmodulin has been identified. ${ }^{11}$

Pharmaceuticals with evolutionary conserved molecular targets are more likely to cause adverse effects in nontarget species. ${ }^{11} \mathrm{~A}$ high-profile example involves the synthetic estrogen $17 \alpha$-ethynilestradiol, which causes feminization in fish at concentra- tion ranges as low as $\mathrm{ng} / \mathrm{L}$; in contrast, in crustaceans, where estrogen receptors have not been found, the effect of the pharmaceutical is minor. ${ }^{12}$ Spironolactone, which targets androgen receptors, was shown to reduce fecundity and cause phenotypic masculinization in fish species, while Daphnia was not affected. ${ }^{13}$ Genes under considerable sexual selection within the reproductive system undergo rapid change, thus leading to variation among vertebrates and invertebrates. In contrast, neuroendocrine mechanisms are relatively well conserved. Consequently, antidepressants for human therapy cause related effects at very low concentrations in a wide number of aquatic vertebrate and invertebrate species. ${ }^{14}$

A series of correlated experiments focused on the effects of different pharmaceuticals on cyclic adenosine monophosphate (cAMP)-dependent signaling in marine mussels. Although used to treat different human pathologies, propranolol (PROP), fluoxetine (FLX), and carbamazepine (CBZ) share the ability to directly or indirectly modulate cAMP intracellular levels. The crucial role of cAMP in mussel physiology was recently reviewed, ${ }^{15}$ and alterations of the cAMP-dependent pathway may interfere with neuroendocrinological modulation of physiological functions, including reproduction, cilia beating, and heart functioning. ${ }^{15}$ 
PROP is a prototypical $\beta$-adrenergic ( $\beta$-AR) antagonist used in human therapies to counteract cardiovascular pathologies. In addition, it is an effective serotonin (5-hydroxythriptamine [5-HT]) receptor antagonist of subtype $5-\mathrm{HT}_{1}$, and through these receptors, serotonin modulates invertebrate physiology at many levels. ${ }^{15}$

PROP bioconcentrates in mussel tissues ${ }^{16}$ and reaches $\mathrm{mg} / \mathrm{L}$ levels in fish blood. ${ }^{17}$ Exposure to PROP at environmentally relevant concentrations (ng/L range) significantly lowered cAMP levels and protein kinase A (PKA) activities in the digestive gland of the mussel Mytilus galloprovincialis. This is consistent with the drug action as a $\beta$-AR blocker, counteracting in vivo the positive effects of adrenergic regulators on the cAMP signaling pathway. In contrast, PROP increased cAMP levels in the mantle and gonads of the mollusks, ${ }^{18}$ consistent with the antagonistic effect on $5-\mathrm{HT}_{1}$ receptors, which are coupled with an inhibitory $G\left(G_{i}\right)$ protein and therefore lead to reduction of cAMP formation upon serotonin binding. These observations indicate that specific effects of environmental pharmaceuticals may be different in different animal tissues, depending on available molecular targets. ${ }^{18}$

Through cAMP modulation, PROP also induced a downregulation of $A B C B$ mRNA expression in the digestive gland of mussels, whereas an overexpression was observed in the mantle and gonads. $A B C B$ encodes the P-glycoprotein, which is a membrane transporter that extrudes xenobiotics from the cells as part of the mussel multi-xenobiotic resistance (MXR) system and has been found to be modulated by cAMP. ${ }^{19}$ The above evidence indicates that, in mussels, PROP interacts with the same molecular pathway detected in humans. In the long term, its effects may be detrimental, altering the ability of mussels to extrude environmental contaminants through the MXR system or, more generally, affecting homeostasis.

FLX is the active ingredient of Prozac ${ }^{\circledR}$, a relatively old and widely prescribed psychoactive drug that acts as a selective serotonin-reuptake inhibitor for the treatment of depression and other mood disorders. The therapeutic goal is to increase serotonin levels within the synaptic cleft; since serotonin is a major neuromodulator in invertebrates, FLX has the potential to impair relevant physiological functions in mussels, including regulation of food intake, metabolism, and reproductive success. ${ }^{20}$
In vivo treatment of mussels with FLX at environmental concentrations ( $\mathrm{ng} / \mathrm{L}$ range) reduced cAMP levels and PKA activity below control values, consistent with the inhibition of adenylyl cyclase (AC) activity by a putative increase of serotonin levels induced by FLX and the consequent occupation of $5-\mathrm{HT}_{1}$ receptors by the agonist. Interestingly, the $5-\mathrm{HT}_{1}$ receptor, coupled to the inhibition of $\mathrm{AC}$, is the sole serotonin receptor subtype pharmacologically demonstrated in invertebrates. ${ }^{15}$

$\mathrm{CBZ}$ is an anticonvulsant and mood-stabilizing drug used primarily in the treatment of epilepsy and bipolar disorders that is consistently found in aquatic environments. Its therapeutic effect, leading to reduction of ion-channel opening, is at least in part mediated by a reduction of cAMP levels through direct inhibition of $\mathrm{AC}$ and consequent reduction of neuronal excitability. ${ }^{21} \mathrm{CBZ}$ has been shown to inhibit $A C$ in mussels and to reduce the expression levels of $A B C B$ mRNA, potentially lowering the detoxification ability of mussels. ${ }^{21}$

The above data confirm the presence and functional role of pharmaceutical targets evolutionarily conserved among invertebrates and humans. Being aware that conservation of a therapeutic target does not necessarily translate to conservation of its function across species, ${ }^{22}$ these results also underline the value of MoA approaches to identify environmental pharmaceuticals of major concern.

\section{Side effects of pharmaceuticals in aquatic fauna: focus on oxidative stress}

CBZ-associated human hepatotoxicity is mediated, at least in part, by oxidative stress characterized by enhanced levels of reactive oxygen species (ROS; e.g., hydroxyl radical, superoxide, anion, and hydrogen peroxide).$^{23} \mathrm{CBZ}$ is metabolized by the hepatic $\mathrm{P} 450$ $3 \mathrm{~A}$ family of microsomal enzymes, and is itself a potent inducer of liver microsomal enzymes.

The drug impaired the health status and induced oxidative stress in the marine clams Venerupis decussata and $V$. philippinarum. ${ }^{24}$ An induction of glutathione reductase (GR), superoxide dismutase (SOD), and cytochrome P450 3A4 activities was found in both species as a result of CBZ exposure. CBZ lowered health status and challenged the antioxidant enzyme system of mussels, as indicated by increased activities of catalase (CAT) and glutathione S-transferase (GST), and accumulation of the oxidation product malondhyaldehyde 
after exposure. ${ }^{21}$ The drug also induced significant oxidative stress in trout liver, where lipid peroxidation, protein carboxylation, and GSH depletion occurred in long-term exposures ( 21 and 42 days). ${ }^{25}$ Moreover, enzyme activities were increased after animal treatments with $\mathrm{CBZ}$ in the $\mu \mathrm{g} / \mathrm{L}$ range, while reduced SOD, CAT, GR, and glutathione peroxidase $(\mathrm{GPx})$ activities were observed at $\mathrm{mg} / \mathrm{L}$ CBZ. ${ }^{26}$ Overall, a bell-shaped response was reported for such detoxification responses. ${ }^{25,26}$

The bimodal effect on antioxidant enzyme activities is not unique for CBZ, and the observed bellshaped response is a hallmark reported in many studies on environmental pharmaceutical effects.

The nonsteroid anti-inflammatory drugs (NSAIDs) ibuprofen (IBU) and diclofenac (DCF) are widely used therapies and consistently found in water bodies worldwide up to $\mu \mathrm{g} / \mathrm{L}$ concentrations. As expected from its MoA in human patients, IBU reduces cyclooxygenase activity in mussels and also induces oxidative stress. ${ }^{27}$ Increases in SOD, CAT, GR, and GST activities were observed after 3 and 7 days of exposure to IBU, while enzyme activities returned to basal levels after 15 days. Similarly, activities of SOD, CAT, and GR were increased by DCF after a 3-day mussel exposure, but returned to basal levels at 7 and 15 days. ${ }^{28}$ IBU and DCF oxidative metabolism favors the formation of superoxide anions, which contribute to the inhibition of antioxidant enzymes activities in the longer term, leading to lipid peroxidation and/or protein carbonylation. ${ }^{27,28}$ Similarly, bell-shaped curves of CAT activities were reported in mussels exposed to increasing concentrations of PROP and FLX. ${ }^{18,20}$

The antibiotics norfloxacin and sulfamethoxazole have been detected in aquatic environments resulting from their prescription for the treatment of urinary tract infection and promote animal growth at subtherapeutic levels. ${ }^{29}$ EROD, GST, and SOD activities were significantly increased by the individual and combined antibiotics in exposed goldfish and the response exhibited bell-shaped concentration-response curves. ${ }^{29}$ In particular, SOD, a key enzyme that protects cells against oxidative damage, was enhanced at low concentrations, suggesting significant ROS production as a consequence of antibiotic treatment. However, at the highest concentrations (as high as $1-10 \mathrm{mg} / \mathrm{L}$ ), the induction was reduced. This pattern is generally explained by the excess of superoxide radicals that are transformed into $\mathrm{H}_{2} \mathrm{O}_{2}$ by SOD, whose accumulation causes oxidation of the cysteines present in the enzyme molecule, thus deactivating SOD. ${ }^{29}$

The redox status of mussels was affected by $17 \beta$-estradiol. Treatment of hemocytes with $17 \beta$-estradiol significantly increased ROS production, leading to oxidative damage exemplified by significantly increased DNA damage, protein carbonylation, and lipid peroxidation, as well as increased mRNA levels of the antioxidant enzymes CAT, SOD, and GST. ${ }^{30}$ Treatment with $17 \beta$-estradiol also altered oxidative pathways in digestive glands of mussels, increasing CAT activities and transcription of metallothionein and CAT mRNAs; interestingly, stimulation of CAT activity and metallothionein transcript expression again showed a bell-shaped dose-response curve. ${ }^{31}$

In conclusion, a number of environmental pharmaceuticals elicit ROS production and trigger antioxidant responses that may be overwhelmed, leading to the accumulation of deleterious oxidation products. Many hypotheses can be postulated regarding the existence of a regulatory pattern that could generate a bell-shaped dose-response curve. The complexity of the oxidative response in aquatic animals is as high as in mammals; however, unlike in humans and rodents, its modulation is poorly known. Recently, a coordinated transcriptional regulation of antioxidant enzyme genes was demonstrated in the eel Anguilla anguilla, ${ }^{32}$ a promising result that needs clarification in fish and in invertebrates.

Furthermore, evidence that effects of many environmental pharmaceuticals occur at lower but not at higher concentrations suggest an adjustment of the range of concentrations used in future ecotoxicological tests.

\section{Other unexpected effects of pharmaceuticals in aquatic fauna}

Oxidative stress is often an unwanted effect of pharmaceutical therapies in humans, and therefore it is not surprising that it takes place in aquatic fauna as well. Moreover, it is conceivable that MoA-related effects are caused in aquatic invertebrates and fish if molecular targets mediating therapeutic effects have been conserved during evolution. However, several investigations found other unexpected effects of pharmaceuticals in aquatic fauna. In these cases, 
yet-unknown molecular targets may be involved, or the same pharmaceutical targets may display different functions in fish or molluscs than in humans.

The fibrate drug gemfibrozil (GEM), a hypolipidemic agent used to decrease serum triglycerides, cholesterol, and very-low-density lipoproteins (VLDLs) and to increase high-density lipoproteins (HDLs) in human medicine, ${ }^{33}$ is widely found in aquatic bodies at $\mathrm{ng} / \mathrm{L}$ to $\mu \mathrm{g} / \mathrm{L}$ concentrations. GEM is a peroxisomal proliferator believed to elicit its effect by binding to the nuclear transcription factor peroxisome proliferator-activated receptor $\alpha$ $(P P A R \alpha)$ and promoting hepatic uptake and metabolism of free fatty acids. ${ }^{34}$ PPARs are a family of ligand-inducible transcription factors that play key roles in modulating the expression of genes involved mainly in lipid homeostasis. Three different PPAR paralogues $(\alpha, \beta$, and $\gamma$ types) have been described in different vertebrate species, including fish. ${ }^{35}$ However, regulation of PPAR-related genes in fish is not sufficiently understood, and nothing has been reported regarding invertebrate orthologs of vertebrate PPARs.

In vivo exposure to GEM induced significant effects on the mussel digestive gland, the key metabolic organ in bivalves, where the drug increased the activity of phosphofructokinase (PFK), pyruvate kinase (PK), CAT, GST, and GR. ${ }^{36}$ In mussel hemocytes, GEM induced lysosomal membrane destabilization, extracellular lysozyme release, nitric oxide (NO) production, and decreased phagocytic activity, while not effecting palmitoyl CoA oxidase activity. ${ }^{36}$ Overall, environmental concentrations of GEM affected immune function, glycolysis, redox balance, and peroxisomal function in mussels.

Unlike what is observed in mammals, peroxisomal proliferation-inducible enzymes (namely, liver peroxisomal acyl-CoA oxidase and CAT) were very weakly induced in the eel $A$. anguilla treated with GEM, and no effect on the endocrine system was observed in terms of plasma steroid levels or testosterone esterification in eel liver. ${ }^{37}$ Again, unlike what is observed in the liver of rodents, GEM induced a moderate antioxidant response (increased CAT, GPx, and GST activities) in goldfish liver and caused no oxidative damage, ${ }^{38}$ supporting the hypothesis that fish and rodents respond differently to peroxisome proliferators. GEM is known to increase HDL plasma concen- trations in humans, while in trout, which have very high HDL levels compared with humans, it lowers the concentration of all plasma lipoproteins (HDLs, low-density lipoproteins (LDLs), VLDLs) by about $70 \%$ and testosterone levels by about $50 \% .{ }^{39}$ Adult zebrafish chronically exposed to 0.5 and $10 \mu \mathrm{g} / \mathrm{L}$ of GEM show decreased reproductive output, atresic oocytes, and altered kidney histology; moreover, when a control F1 female was crossed with a GEM-exposed F1 male, 50\% fewer embryos were produced, male courtship was reduced, and sperm had shorter head lengths with respect to controls. ${ }^{39}$ It can be concluded that environmental pharmaceuticals, even at low doses, may cause effects on nontarget animals that cannot be predicted on the basis of the therapeutic MoA. These may pose serious and unpredictable risks to wildlife, especially when detected in offspring not directly exposed to the compounds.

An active pharmaceutical detected in wastewater, FLX bioaccumulates in brain, liver, and muscle tissues of wild-caught fish. ${ }^{40}$ By inhibiting serotonin reuptake at the synaptic level, FLX modifies fish behavior and exerts anorexigenic effects at environmental concentrations. Indeed, it regulates food intake and energy metabolism, with increased expression in corticotropin-releasing factor and decreased expression of neuropeptide $\mathrm{Y}^{41}$

In goldfish males exposed to FLX, a reduced sperm volume was also documented. ${ }^{42}$ Moreover, a strong reduction in plasma testosterone levels was found, explained by the concomitant increase of aromatase mRNA expression, aromatase activity, and estrogen receptors in liver. ${ }^{42}$ Therefore, FLX alters the male reproductive axis, lowering testosterone levels and favoring estradiol and vitellogenin production, and can be included in the group of environmental chemicals causing feminization effects. $^{42,43}$

DCF was found to be the cause of massive death of Asian vultures after ingestion of drug-treated goats. ${ }^{44}$ A known side effect of DCF in human patients treated with high doses or for long periods is renal toxicity, and the same effects were detected in dead vultures. However, no mass mortality was ever reported for other animals, not even for goats subjected to direct treatments. More recently, it was reported that vultures are CYP2C9 deficient (or have reduced activity of the enzyme), meaning they may be far more sensitive to NSAIDs compared with 
other species. ${ }^{45}$ Therefore, pharmacokinetics have a role to play in determining different susceptibility to pharmaceuticals, as well as possible unexpected effects.

These studies indicate that the MoAs of pharmaceuticals is a powerful tool for prioritizing chemicals of concern; however, its extrapolation from mammals to mollusks requires some caution. Indeed, additional targets and effects, which at present cannot be predicted, have to be identified by appropriate toxicological experiments. Nevertheless, further insights into comparative physiology were provided, since pharmaceuticals used as laboratory tools facilitated the exploration of undocumented pathways and the acquisition of new information in aquatic vertebrates and invertebrates.

\section{Conclusions and perspectives}

The issue of the impact of environmental pharmaceuticals, neglected for a long time despite the chemical evidence, is now the focus of different approaches aimed at assessing the risk posed to human and ecosystem health. A cascade of suggestions was recently proposed to identify pharmaceuticals of high concern, related to the MoA, the adverse outcome pathway (AOP), and more recently to the biological read-across hypothesis. ${ }^{46}$ This latter includes both the MoA and AOP concepts, and "stipulates that a drug will have an effect in nontarget organisms only if the molecular targets have been conserved, resulting in a pharmacological effect only if plasma concentrations are similar to human therapeutic concentrations." ${ }^{\prime 6}$ Because chemical safety data are more readily available for pharmaceuticals than any other class of environmental contaminants, biological read-across approaches appear particularly promising. The scientific community, however, must develop more robust experimental data for testing the read-across hypothesis and developing predictive models. ${ }^{46}$ It has to be taken into account that pharmaceutical effects on wildlife may occur at lower concentrations than in humans, ${ }^{18,20,47,48}$ and eventually disappear at higher concentrations. These effects may be displayed through specific mechanisms or side/unexpected routes that should be elucidated.

In conclusion, the MoAs of pharmaceuticals provide a unique opportunity to develop an understanding of the relationship between molecular, cellular, and organism end points in the natural environment. Undoubtedly, pharmaceuticals in water may cause adverse effects on nontarget animals at concentrations lower than those predicted; therefore, new efforts require integration between researchers, risk assessors, and regulators in order to identify research needs and estimate risk as a result of pharmaceutical release into the aquatic environment. For further discussion on the main aspects related to this topic, selected reviews are recommended. ${ }^{3,6-8,14,43,46}$

\section{Acknowledgments}

I am grateful to the young collaborators who worked in my laboratory and obtained a significant part of the data reviewed above. I express my sincere gratitude to T.W. Moon (University of Ottawa), who introduced me to this field of research and contributed with helpful discussions.

\section{Conflicts of interest}

The author declares no conflicts of interest.

\section{References}

1. Daughton, C.G. \& T.A. Ternes. 1999. Pharmaceuticals and personal care products in the environment: agents of subtle changes? Environ. Health Perspect. 107: 907-938.

2. Zuccato, E., S. Castiglioni, R. Fanelli, et al. 2006. Pharmaceuticals in the environment in Italy: causes, occurrence, effects and control. Environ. Sci. Pollut. Res. 13: 15-21.

3. Santos, L.H.M.L.M., A.N. Araujoa, A. Fachini, et al. 2010. Ecotoxicological aspects related to the presence of pharmaceuticals in the aquatic environment. J. Hazard. Mat. 175: 45-95.

4. Walraven, N. \& R.W. Laane. 2009. Assessing the discharge of pharmaceuticals along the Dutch coast of the North Sea. Rev. Environ. Contam. Toxicol. 199: 1-18.

5. Martinez J.L. 2009. Environmental pollution by antibiotics and by antibiotic resistance determinants. Environ. Pollut. 157: 2893-2902.

6. Fent, K., A.A. Weston \& D. Caminada. 2006. Ecotoxicology of human pharmaceuticals. Aquat. Toxicol. 76: 122-159.

7. Glassmeyer, S.T., D.W. Kolpin, E.T. Furlong \& M.J. Focazio. 2008. Environmental presence and persistence of pharmaceuticals: an overview. In Fate of Pharmaceuticals in the Environment and in Water Treatment Systems: p. 1-45. Boca Raton, FL: CRC Press, Taylor and Francis Group.

8. Brooks, B.W., J.P. Berninger, A.J. Ramirez \& D.B. Huggett. 2012. Perspectives on human pharmaceuticals in the environment. In Human Pharmaceuticals in the Environment: Current and Future Perspectives: p. 1-16. New York: Springer.

9. Brooks, B.W., P.K. Turner, J.K. Stanley, et al. 2003. Waterborne and sediment toxicity of fluoxetine to selected organisms. Chemosphere 52: 135-142. 
10. Miège, C., J.M. Choubert, L. Ribeiro, et al. 2009. Fate of pharmaceuticals and personal care products in wastewater treatment plants-conception of a database and first results. Environ. Pollut. 157: 1721-1726.

11. Furuhagen, S., A. Fuchs, E. Lundstrom Belleza, et al. 2014. Are Pharmaceuticals with evolutionary conserved molecular drug targets more potent to cause toxic effects in non-target organisms? PLOS ONE 9: e105028. doi:10.1371/journal.pone. 0105028

12. Jukosky, J.A., M.C. Watzin \& J.C. Leiter 2008. Elevated concentrations of ethinylestradiol, 17 beta-estradiol, and medroxyprogesterone have little effect on reproduction and survival of Ceriodaphnia dubia. Bull. Environ. Cont. Toxicol. 81: 230-235.

13. LaLone, C.A., D.L. Villeneuve, J. E. Cavallin, et al. 2013. Cross-species sensitivity to a novel androgen receptor agonist of potential environmental concern, spironolactone. 2013. Environ. Toxicol. Chem. 32: 2528-2541.

14. Fong, P.P. \& A.T. Ford 2014. The biological effects of antidepressants on the molluscs and crustaceans: a review. Aquat. Toxicol. 151: 4-13.

15. Fabbri, E. \& A. Capuzzo. 2010. Cyclic AMP signaling in bivalve molluscs: an overview. J. Exp. Zool. A Ecol. Genet. Physiol. 313: 179-200.

16. Ericson, H., G. Thorsén \& L. Kumblad. 2010. Physiological effects of diclofenac, ibuprofen and propranolol on Baltic Sea blue mussels. Aquat. Toxicol. 99: 223-231.

17. Giltrow, E., P.D. Eccles, M.J. Winter, et al. 2009. Chronic effects assessment and plasma concentrations of the betablocker propranolol in fathead minnows (Pimephales promelas). Aquat. Toxicol. 95: 195-202.

18. Franzellitti, S., S. Buratti, P. Valbonesi, et al. 2011. The $\beta$-blocker propranolol affects cAMP-dependent signaling and induces the stress response in Mediterranean mussels, Mytilus galloprovincialis. Aquat. Toxicol. 101: 299-308.

19. Franzellitti, S. \& E. Fabbri. 2013. Cyclic-AMP mediated regulation of $A B C B$ mRNA expression in mussel haemocytes. PLoS One. 8: e61634-e61642.

20. Franzellitti, S., S. Buratti, M. Capolupo, et al. 2014. An exploratory investigation of various modes of action and potential adverse outcomes of fluoxetine in marine mussels. Aquat. Toxicol. 151: 14-26.

21. Martin-Diaz, L., S. Franzellitti, S. Buratti, et al. 2009. Effects of environmental concentrations of the antiepilectic drug carbamazepine on biomarkers and cAMP-mediated cell signaling in the mussel Mytilus galloprovincialis. Aquat Toxicol. 94: 177-185.

22. Margiotta-Casaluci, L., R.E. Hannah \& J.P. Sumpter. 2013. Mode of action of human pharmaceuticals in fish: the effects of the 5-alpha-reductase inhibitor, dutasteride, on reproduction as a case study. Aquat. Toxicol. 128-129: 113-123.

23. Santos, N.A., W.S. Medina, N.M. Martins, et al. 2008. Involvement of oxidative stress in the hepatotoxicity induced by aromatic antiepileptic drugs. Toxicol. In Vitro. 22: 1820 1824 .

24. Almeida, A., V. Calisto, V.I. Esteves, et al. 2014. Presence of the pharmaceutical drug carbamazepine in coastal systems: effects on bivalves. Aquat. Toxicol. 156: 74-87.
25. Li, Z.H., V. Zlabek, J. Velisek, et al. 2009. Responses of antioxidant status and $\mathrm{Na}+-\mathrm{K}+-$-ATPase activity in gill of rainbow trout, Oncorhynchus mykiss, chronically treated with carbamazepine. Chemosphere. 77: 1476-1481.

26. Li, Z.H., V. Zlabek, J. Velisek, et al. 2010. Physiological condition status and muscle-based biomarkers in rainbow trout (Oncorhynchus mykiss), after long-term exposure to carbamazepine. J. Appl. Toxicol. 30: 197-203.

27. Gonzalez-Rey, M. \& M.J. Bebianno. 2012. Does nonsteroidal anti-inflammatory (NSAID) ibuprofen induces antioxidant stress and endocrine disruption in mussel Mytilus galloprovincialis? Environ. Toxicol. Pharmacol. 33: 361-371.

28. Gonzalez-Rey, M. \& M.J. Bebianno. 2014. Effects of nonsteroidal anti-inflammatory drug (NSAID) diclofenac exposure in mussel Mytilus galloprovincialis. Aquat. Toxicol. 148: $221-230$.

29. Liu, J., G. Lu, D. Wu \& Z. Yan. 2014. A multi-biomarker assessment of single and combined effects of norfloxacin and sulfamethoxazole on male goldfish (Carassius auratus). Ecotoxicol. Environ. Saf. 102: 12-17.

30. Koutsogiannaki, S., S. Franzellitti, E. Fabbri \& M. Kaloyianni. 2014. Oxidative stress parameters induced by exposure to either cadmium or 17 $\beta$-estradiol on Mytilus galloprovincialis hemocytes. The role of signaling molecules. Aquat. Toxicol. 146: 186-195.

31. Canesi, L., C. Borghi, R. Fabbri, et al. 2007. Effects of 17 betaestradiol on mussel digestive gland. Gen. Comp. Endocrinol. 153: 40-46.

32. Giuliani, M.E. \& F. Regoli. 2014. Identification of the Nrf2Keap 1 pathway in the European eel Anguilla anguilla: role for a transcriptional regulation of antioxidant genes in aquatic organisms. Aquat. Toxicol. 150: 117-123.

33. Spencer, C.M. \& L.B. Barradell. 1996. Gemfibrozil: a reappraisal of its pharmacological properties and place in the management of dyslipidaemia. Drugs. 51: 982-1018.

34. Martin, G., K. Schoonjans, A.M. Lefebvre, et al. 1997. Coordinate regulation of the expression of the fatty acid transport protein and acyl-CoA synthetase genes by PPAR $\alpha$ and PPAR $\gamma$ activators. J. Biol. Chem. 272: 28210-28217.

35. Oku, H. \& T. Umino. 2008. Molecular characterization of peroxisome proliferator-activated receptors (PPARs) and their gene expression in the differentiating adipocytes of red sea bream Pagrus major. Comp. Biochem. Physiol. B Biochem. Mol. Biol. 151: 268-277.

36. Canesi, L., L.C. Lorusso, C. Ciacci, et al. 2007. Effects of blood lipid lowering pharmaceuticals (bezafibrate and gemfibrozil) on immune and digestive gland functions of the bivalve mollusc, Mytilus galloprovincialis. Chemosphere 69: 994-1002.

37. Lyssimachou, A., R. Thibaut, E. Gisbert \& C. Porte. 2014. Gemfibrozil modulates cytochrome $\mathrm{P} 450$ and peroxisome proliferation-inducible enzymes in the liver of the yellow European eel (Anguilla anguilla). Environ. Sci. Pollut. Res. Int. 21: 862-871.

38. Prindiville, J.S., J.A. Mennigen, J.M. Zamora, et al. 2011. The fibrate drug gemfibrozil disrupts lipoprotein metabolism in rainbow trout. Toxicol. Appl. Pharmacol. 251: 201-208. 
39. Galus, M., S. Rangarajan, A. Lai, et al. 2014. Effects of chronic, parental pharmaceutical exposure on zebrafish (Danio rerio) offspring. Aquat. Toxicol. 151: 124-134.

40. Brooks, B.W. 2014. Fish on Prozac (and Zoloft): ten years later. Aquat. Toxicol. 151: 61-67.

41. Mennigen, J.A., J. Sassine, V.L. Trudeau \& T.W. Moon. 2010. Waterborne fluoxetine disrupts feeding and energy metabolism in the goldfish Carassius auratus. Aquat. Toxicol. 100: 128-137.

42. Mennigen, J.A., W.E. Lado, J.M. Zamora, et al. 2010. Waterborne fluoxetine disrupts the reproductive axis in sexually mature male goldfish Carassius auratus. Aquat. Toxicol. 100: 354-364.

43. Kloas, W., R. Urbatzka, R. Opitz, et al. 2009. Endocrine disruption in aquatic vertebrates. Ann. N. Y. Acad. Sci. 1163: 187-200.

44. Oaks, J.L., M. Gilbert, M.Z. Virani, et al. 2004. Diclofenac residues as the cause of vulture population decline in Pakistan. Nature. 427: 630-633.

45. Naidoo, V., L. Venter, K. Wolter, et al. 2010. The toxicokinetics of ketoprofen in Gyps coprotheres: toxicity due to zero-order metabolism. Arch. Toxicol. 84: 761-766.

46. Rand-Weaver, M., L. Margiotta-Casaluci, A. Patel, et al. 2013. The read-across hypothesis and environmental risk assessment of pharmaceuticals. Environ. Sci. Technol. 47: 1138411395.

47. Di Poi, C., A.S. Darmaillacq, L. Dickel, et al. 2013. Effects of perinatal exposure to waterborne fluoxetine on memory processing in the cuttlefish Sepia officinalis. Aquat. Toxicol. 132-133: 84-91.

48. Bossus, M.C., Y.Z. Guler, S.J. Short, et al. 2014. Behavioural and transcriptional changes in the amphipod Echinogammarus marinus exposed to two antidepressants, fluoxetine and sertraline. Aquat. Toxicol. 151: 46-56. 